\title{
Brake power, brake spesific fuel consumption, dan brake thermal efficiency mesin diesel injeksi langsung berbahan bakar solar- jatropa-butanol
}

\author{
Syarifudin $^{1 *}$, Syaiful ${ }^{2}$, Firman Lukman Sanjaya ${ }^{3}$ \\ 1,3Program Studi Teknik Mesin, Politeknik Harapan Bersama \\ Jl. Mataram no.9, Kota Tegal, Jawa Tengah, Indonesia \\ 2Jurusan Teknik Mesin, Fakultas Teknik, Universitas Diponegoro \\ JI. Prof. Soedarto SH, Tembalang, Semarang, Indonesia \\ *Corresponding author. masudinsyarif88@gmail.com
}

\begin{abstract}
Jatropha is proven to reduce dependence on diesel fuel. Jatropha oil is widely used as a mixture of diesel fuel. However, low heating value and high viscosity result in lower engine performance and higher carbon black emissions than pure diesel fuel. Alcohol groups such as butanol have low viscosity properties and oxygen and cetane numbers close to diesel fuel. The use of butanol as an additive to diesel-jatropha mixed fuels is expected to improve engine performance. This study aims to observe brake power, brake specific fuel consumption, and brake thermal efficiency of diesel engines using diesel-jatropha-butanol mixed fuel. Jatropha used 10\%, 20\% and 30\%. While the butanol used is 5\%, 10\%, and 15\% based on volume. The research increased in a brake power value of $2.22 \%$. The decrease in brake specific fuel consumption was $4.81 \%$ and the increase in brake thermal efficiency was $10.85 \%$.
\end{abstract}

Keywords : jatropha, viscosity, performance, soot, butanol.

\section{Abstrak}

Jatropa terbukti dapat mengurangi ketergantungan bahan bakar solar. Minyak jatropa banyak digunakan sebagai bahan campuran bahan bakar solar. Namun, nilai kalor yang rendah dan viskositas yang tinggi mengakibatkan prestasi mesin menjadi lebih rendah dan emisi jelaga menjadi lebih tinggi dibandingkan bahan bakar solar murni. Kelompok alkohol seperti butanol memiliki propertis viskositas yang rendah dan kandungan oksigen dan cetane number yang mendekati bahan bakar solar. Penggunan butanol sebagai additif pada bahan bakar campuran solar-jatropa diharapkan dapat meningkatkan prestasi mesin. Penelitian ini bertujuan mengobservasi brake power, brake spesific fuel consumption, dan brake thermal efficiency mesin diesel menggunakan bahan bakar campuran solar-jatropa-butanol. Jatropa yang digunakan sebesar 10\%, 20\% dan 30\%. Sedangkan butanol yang digunakan sebesar 5\%, 10\%, dan $15 \%$ berbasis volume. Penelitian menghasilkan nilai peningkatan brake power sebesar $2,22 \%$. Penurunan brake spesific fuel consumption sebesar $4,81 \%$ dan peningkatan brake thermal efficiency sebesar 10,85\%.

Kata kunci: jatropa, viskositas, prestasi, jelaga, butanol

\section{Pendahuluan}

Jatropa merupakan bahan bakar alternatif yang dapat dijadikan sebagai bahan pengganti bahan bakar solar. Jatropa terus diminati seiring keterbatasan stok bahan bakar fosil seperti solar dan peningkatan volume kendaraan bermotor. Jatropa dapat diproduksi dari tanaman jarak yang cocok dibudidayakan di negara tropis seperti Indonesia. Jatropa memiliki propertis yang mendekati bahan bakar solar sehingga mengurangi proses penyesuaian pada mesin diesel [1]. Angka setana yang tinggi sekitar 41,8 membuat jatropa cocok sebagai bahan campuran bahan bakar solar [2]. Selain itu, 
kandungan oksigen yang tinggi pada jatropa sesuai dengan syarat pembakaran [3].

Menurut Rashed dkk., (2016) [4], penggunaan bahan bakar campuran solarjatropa menghasilkan performa yang mendekati bahan bakar solar murni. Hal ini akibat angka setana dan kandungan oksigen yang tinggi dalam jatropa. Hasil positif yang sama juga diperoleh Gomma (2011) [5], bahwa pengujian mesin diesel dengan bahan bakar campuran solar-jatropa menghasilkan effisiensi termal yang lebih besar daripada bahan bakar solar murni. Sementara menurut Eka Darmana dkk (2013) [6] penggunaan jatropa sebagai bahan campuran bahan bakar solar menyebabkan penurunan nilai brake power mesin diesel. Tingginya viskositas jatropa menurunkan kualitas atomisasi bahan bakar yang berdampak pada pembakaran yang buruk [7].

Kelompok alkohol seperti butanol memiliki propertis rendah viskositas yang mendukung untuk mengurangi tingginya viskositas pada jatropa. Selain itu, angka setana yang mendekati bahan bakar solar dan kandungan oksigen yang tinggi mendukung bahwa alkohol butanol dapat meningkatkan kualitas bahan bakar campuran solar-jatropa [8]. Menurut Syarifudin dkk (2018) [9], penambahan butanol pada bahan bakar campuran solarjatropa menghasilkan emisi smoke yang lebih rendah. Hal ini disebabkan kandungan oksigen yang tinggi memicu terjadinya oksidasi karbon sehingga menekan pembentukan jelaga [10]. Tendensi yang sama juga terjadi pada penelitian Ibrahim Amr (2017) [11], dan El Seesy \& Hasan (2019) [12].

Kandungan butanol pada bahan bakar solar campuran jatropa membawa dampak positif pada sisi emisi gas buang yang dihasilkan mesin diesel. Oleh karena itu, penelitian ini mengobservasi sisi prestasi kerja mesin yang ditunjukkan oleh nilai brake power (BP), brake specific fuel consumption (BSFC), dan brake thermal efficiency (BTE).

\section{Tinjuaun Teoritis}

\section{Brake Power}

Brake power (daya) adalah besarnya kerja telah dilakukan tiap satuan waktu.

$$
P=2 \pi \frac{N}{60} \times T \times 10^{-3}
$$

Dimana $P$ adalah daya (k.W), $T$ adalah torsi (N.m) dan $N$ adalah putaran kerja (rpm) [13].

\section{Brake Spesific Fuel Consumption}

Brake spesific fuel consumption adalah laju aliran massa persatuan daya [13].

$$
B S F C=\frac{m f}{P}
$$

Dimana BSFC adalah konsumsi bahan bakar (kg/kW.jam), dan $m f$ adalah laju aliran massa $(\mathrm{kg} / \mathrm{jam})$.

\section{Brake Thermal Efficiency}

Brake Thermal Efficiency (BTE) adalah perbandingan antara kerja mesin/daya (P) yang dihasilkan persiklus terhadap jumlah suplay energi per siklus yang dilepaskan selama pembakaran. Suplai energi yang dilepas selama pembakaran $\left(m_{f}\right)$ adalah massa bahan bakar yang disuplay per siklus dikalikan dengan nilai panas dari bahan bakar (QHV) [13].

$$
B T E=\frac{P}{\dot{m}_{f} Q_{H V}}
$$

Dimana BTE adalah efisiensi termal (\%), QHv adalah nilai kalor dari bahan bakar $(\mathrm{MJ} / \mathrm{kg})$.

\section{Metode Penelitian}

Bahan bakar yang digunakan adalah bahan bakar solar yang diperoleh dari Stasiun Pengisian Bahan bakar Umum (SPBU), jatropa dan alkohol butanol yang diperoleh dari toko kimia di Kota Semarang yang masing-masing mempunyai propertis seperti yang terlihat pada Tabel 1 . 
Tabel 1. Propertis bahan bakar

\begin{tabular}{clccc}
\hline No & \multicolumn{1}{c}{ Propertis } & Solar & Jatropa & Butanol \\
\hline 1 & Angka Setana & 48 & 41,8 & 23,4 \\
\hline 2 & Kadar Air $(\% \mathrm{v})$ & 0,05 & 3,16 & 34,22 \\
\hline 3 & $\begin{array}{l}\text { Viskositas } \\
\text { (pada suhu } \\
\left.40^{\circ} \mathrm{C}(\mathrm{mPa} . \mathrm{s})\right)\end{array}$ & $\begin{array}{c}2,0- \\
5,0\end{array}$ & 3,23 & 2,05 \\
\hline 4 & $\begin{array}{l}\text { Nilai Kalor } \\
(\mathrm{MJ} / \mathrm{kg})\end{array}$ & 45,21 & 37,97 & 33,21 \\
\hline 5 & $\begin{array}{l}\text { Kandungan } \\
\text { Oksigen }(\%)\end{array}$ & - & 10,9 & 21,69 \\
\hline 6 & Titik Nyala $\left({ }^{\circ} \mathrm{C}\right)$ & 60 & 198 & 38 \\
\hline
\end{tabular}

Komposisi bahan bakar yang digunakan adalah D100, DJ10, DJ10B15, DJ20, DJ20B15, DJ30, DJ30B15. Berikut detail volume komposisi bahan bakar tersebut.

Tabel 2. Komposisi bahan bakar

\begin{tabular}{clccc}
\hline \multirow{2}{*}{ No } & \multirow{2}{*}{$\begin{array}{c}\text { Bahan } \\
\text { bakar }\end{array}$} & \multicolumn{3}{c}{ Volume $(\mathrm{ml})$} \\
\cline { 3 - 5 } 1 & D100 & 1000 & 0 & 0 \\
\hline 2 & DJ10 & 900 & 100 & 0 \\
\hline 3 & DJ10B5 & 850 & 100 & 50 \\
\hline 4 & DJ10B10 & 800 & 100 & 100 \\
\hline 5 & DJ10B15 & 750 & 100 & 150 \\
\hline 6 & DJ20 & 800 & 200 & 0 \\
\hline 7 & DJ20B5 & 750 & 200 & 50 \\
\hline 8 & DJ20B10 & 700 & 200 & 100 \\
\hline 9 & DJ20B15 & 650 & 200 & 150 \\
\hline 10 & DJ30 & 700 & 300 & 0 \\
\hline 11 & DJ30B5 & 650 & 300 & 50 \\
\hline 12 & DJ30B10 & 600 & 300 & 100 \\
\hline 13 & DJ30B15 & 550 & 300 & 150 \\
\hline
\end{tabular}

Pengujian dilakukan di Laboratorium Thermo Fluida, Universitas Diponegoro Semarang. Mesin yang digunakan adalah mesin diesel Isuzu 4JB1, 4 silinder, 4 langkah, kapasitas $2800 \mathrm{cc}$. Adapun Dynamometer yang digunakan adalah Dynotest tipe hidraulik merk Dynamite land \& sea.

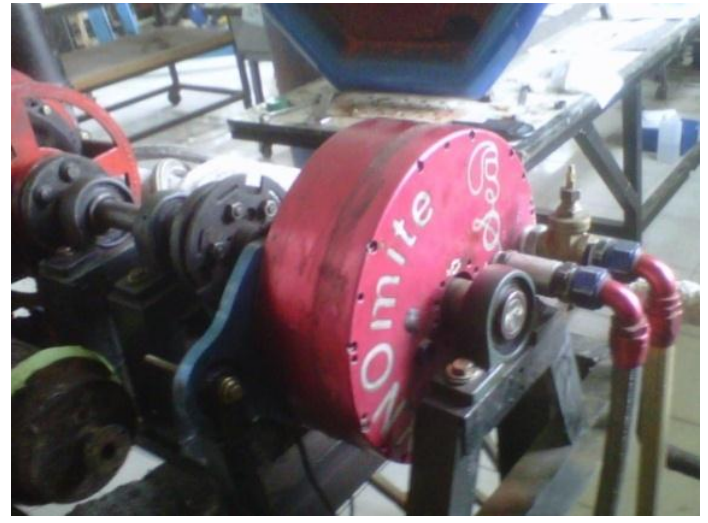

Gambar 1. Dinamometer

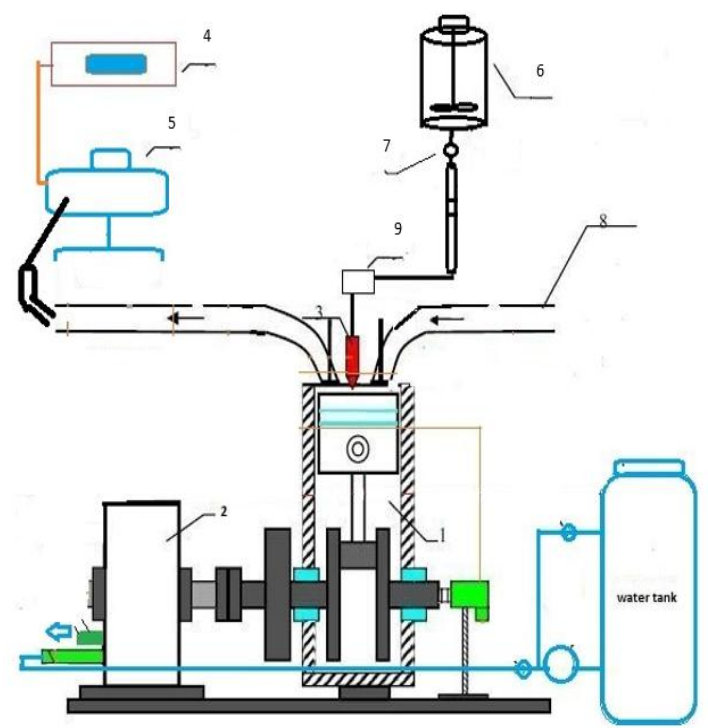

Gambar 2. Skema pengujian

Keterangan :

1. Mesin diesel

2. 1 Set Dinamometer

3. Injektor

4. Gas analyzer Stargass 898

5. Smoke meter

6. Mixer bahan bakar

7. Katup bahan bakar

8. Intake manifold

Mesin diesel dan perlengkapannya disusun seperti pada Gambar 2. Mesin diesel dinyalakan dan diatur pada putaran mesin 2500 secara konstan. Campuran bahan bakar yang sudah dibuat sesuai komposisi dituangkan ke dalam mixer sehingga menjadi homogen. Katup ini dibuka sehingga bahan bakar mengalir ke mesin. Gaya yang ditampilkan pada display dinamometer dijadikan sebagai variabel untuk menghitung daya dan torsi. Untuk 
mengetahui laju konsumsi bahan bakar, dilakukan pengukuran waktu konsumsi setiap $30 \mathrm{ml}$ bahan bakar. Selanjutnya hasil pengukuran daya dan perhitungan laju konsumsi bahan bakar dijadikan bahan untuk menghitung efisiensi termal mesin diesel.

\section{Hasil dan Pembahasan}

1. Brake Power mesin diesel berbahan bakar solar dengan kandungan jatropa $10 \%, 20 \%$, 30\% dan butanol 5\%, 10\%, dan $15 \%$.

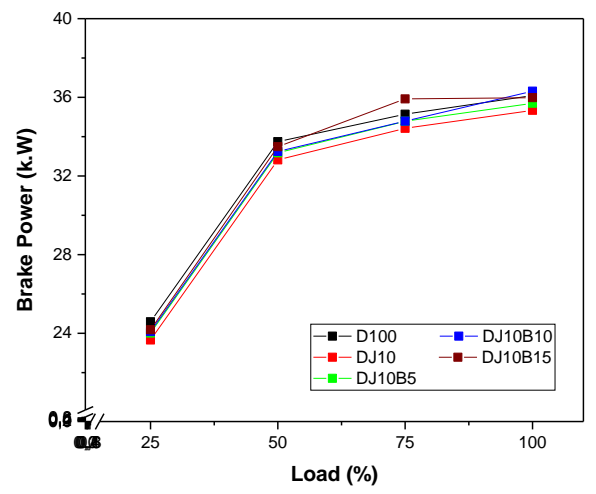

Gambar 3. Brake power mesin diesel berbahan bakar solar dengan kandungan jatropa $10 \%$ dan butanol 5\%,10\%,15\%

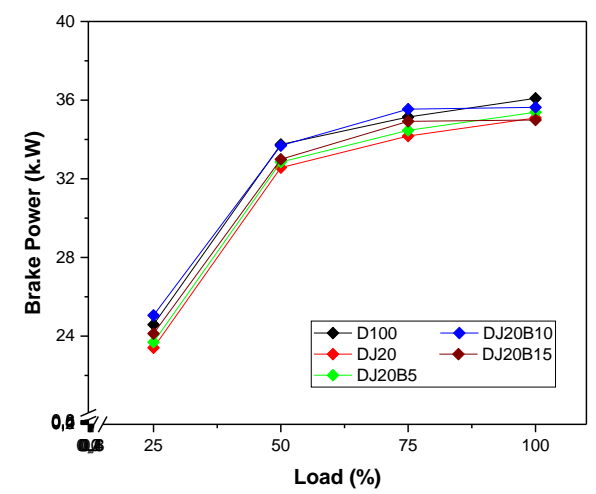

Gambar 4. Brake power mesin diesel berbahan bakar solar dengan kandungan jatropa $20 \%$ dan butanol 5\%,10\%,15\%

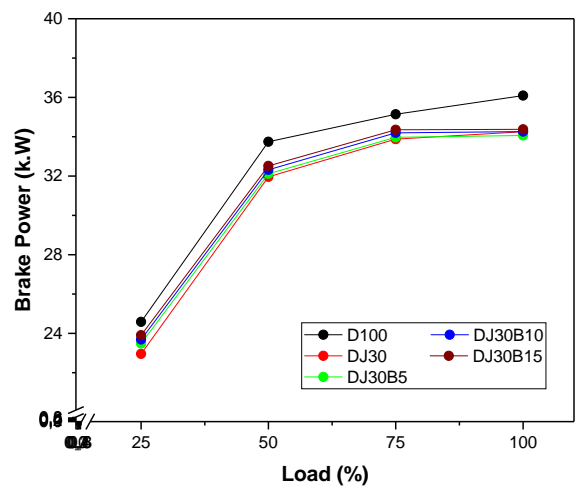

Gambar 5. Brake power mesin diesel berbahan bakar solar dengan kandungan jatropa 30\% dan butanol 5\%,10\%,15\%

Gambar 3, Gambar 4, dan Gambar 5 adalah presentasi brake power mesin diesel berbahan bakar solar campuran jatropa dan butanol. Secara umum, brake power mesin diesel terjadi peningkatan seiring kenaikan pembebanan mesin. Hal ini akibat berkurangnya FAR pada beban yang lebih tinggi saat penambahan suplai bahan bakar ke dalam ruang bakar [14].

Penggunaan bahan bakar solar dengan campuran jatropa menunjukkan hasil brake power yang lebih rendah dibandingkan solar murni (D100)[15]. Akan tetapi, penambahan butanol pada bahan bakar campuran solar-jatropa mengakibatkan nilai brake power meningkat, meskipun masih lebih rendah dibandingkan solar murni D100. Semakin tinggi kandungan butanol peningkatan nilai brake power semakin tinggi pula. Viskositas yang rendah pada butanol mengurangi efek buruk kandungan jatropa sehingga memperbaiki kualitas bahan bakar [16]. Selain itu, kandungan oksigen yang tinggi pada butanol meningkatkan kualitas proses pembakaran di dalam ruang bakar [17].

Peningkatan nilai brake power pada penggunaan bahan bakar solar dengan campuran jatropa 10\% dan butanol 5\%, 10\% dan 15\% (Gambar 3) diperoleh pada bahan bakar DJ20B15 sebesar 2,22\% pada pembebanan $75 \%$. Sedangkan peningkatan nilai brake power tertinggi pada penggunaan bahan bakar solar dengan campuran jatropa $20 \%$ dan butanol 5\%, 10\%, dan $15 \%$ 
(Gambar 4) diperoleh pada bahan bakar DJ20B10 sebesar $1,92 \%$ pada pembebanan $25 \%$. Adapun pengujian brake power dengan kandungan jatropa $30 \%$ dan butanol $5 \%, 10 \%$ dan $15 \%$ juga mengalami peningkatan. Akan tetapi nilainya masih lebih rendah dibandingkan D100.

2. Brake Specific Fuel Consumption mesin diesel berbahan bakar solar dengan kandungan jatropa 10\%, 20\%, 30\% dan butanol $5 \%, 10 \%$ dan $15 \%$.

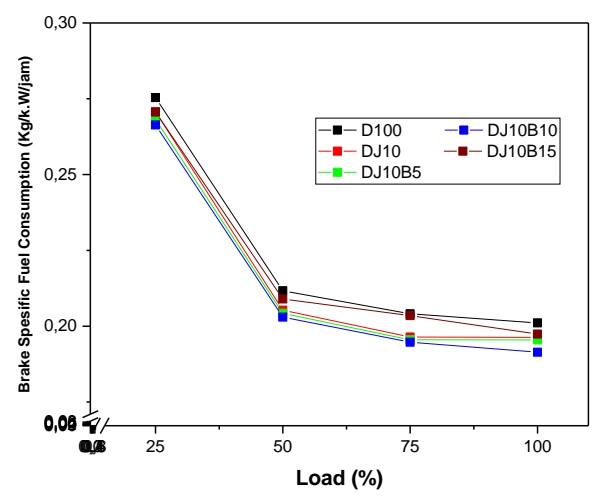

Gambar 6. Brake spesific fuel consumption mesin diesel berbahan bakar solar dengan kandungan jatropa $10 \%$ dan butanol $5 \%, 10 \%, 15 \%$

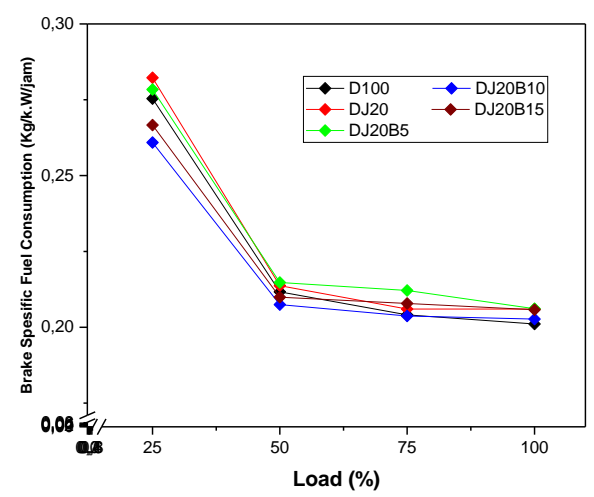

Gambar 7. Brake spesific fuel consumption mesin diesel berbahan bakar solar dengan kandungan jatropa $20 \%$ dan butanol $5 \%, 10 \%, 15 \%$

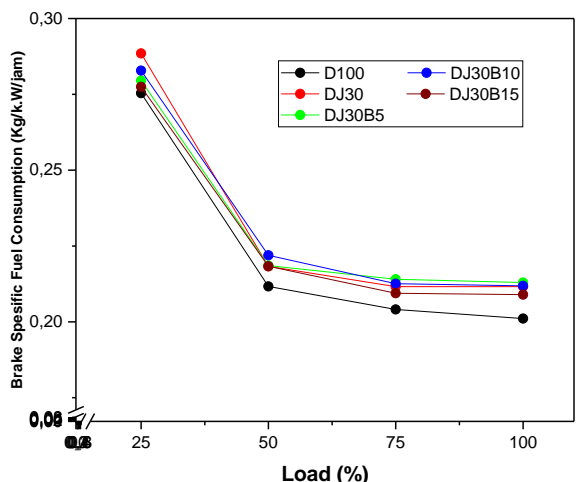

Gambar 8. Brake spesific fuel consumption mesin diesel berbahan bakar solar dengan kandungan jatropa $30 \%$ dan butanol $5 \%, 10 \%, 15 \%$

Pengujian Brake spesific fuel consumption (BSFC) mesin diesel berbahan bakar solar campuran jatropa dan butanol mempresentasikan penurunan nilai BSFC seiring kenaikan pembebanan pada mesin. BSFC mesin diesel dengan kandungan jatropa $20 \%$ dan $30 \%$ juga terjadi penurunan meskipun nilainya lebih besar dibandingkan saat menggunakan bahan bakar solar murni (D100). Viskositas yang tinggi pada jatropa memperburuk efektifitas penginjeksian bahan bakar sehingga meningkatkan konsumsi bahan bakar [18]. Selain itu, nilai kalor yang lebih rendah dari bahan bakar solar merupakan penyebab nilai BSFC bahan bakar solar campuran jatropa menjadi lebih tinggi dibandingkan bahan bakar solar murni (D100) [19]. Akan tetapi, adanya kandungan butanol mengurangi besarnya nilai BSFC mesin diesel berbahan bakar solar campuran jatropa. Kandungan oksigen yang tinggi dan viskositas yang rendah pada butanol membantu dalam pembentukn campuran bahan bakar-udara menjadi homogen sehingga proses oksidasi pembakaran di ruang bakar menjadi sempurna. Hal ini menjadikan brake power meningkat dan BSFC mesin diesel menurun [20,11].

Pengujian BSFC dengan kandungan jatropa $10 \%$ dan butanol 5\%, 10\% dan $15 \%$ (Gambar 6) menunjukkan penurunan nilai BSFC dibandingkan D100. Penurunan 
tertinggi terjadi pada penggunaan bahan bakat DJ10B10 sebesar $4,81 \%$ saat pembebanan mesin $100 \%$ Sedangkan penurunan tertinggi pada penggunaan bahan bakar dengan campuran jatropa $20 \%$ (Gambar 7) terlihat pada bahan bakar DJ20B15 sebesar 3,16\% saat pembebanan 25\%. Pengujian BSFC dengan kandungan jatropa $30 \%$ juga terlihat menurun meskipun nilainya lebih tinggi dibandingkan bahan bakar solar murni (D100).

3. Brake thermal efficiency mesin diesel berbahan bakar solar dengan kandungan jatropa 10\%, 20\%, 30\% dan butanol 5\%, $10 \%$, dan $15 \%$.

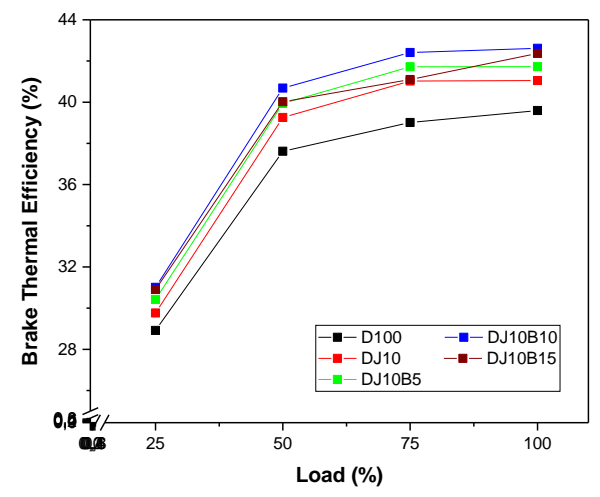

Gambar 9. Brake thermal efficiency mesin diesel berbahan bakar solar dengan kandungan jatropa $10 \%$ dan butanol $5 \%, 10 \%, 15 \%$

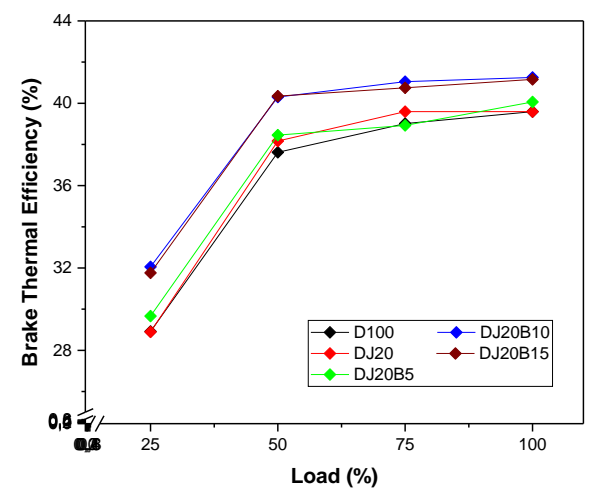

Gambar 10. Brake thermal efficiency mesin diesel berbahan bakar solar dengan kandungan jatropa $20 \%$ dan butanol $5 \%, 10 \%, 15 \%$

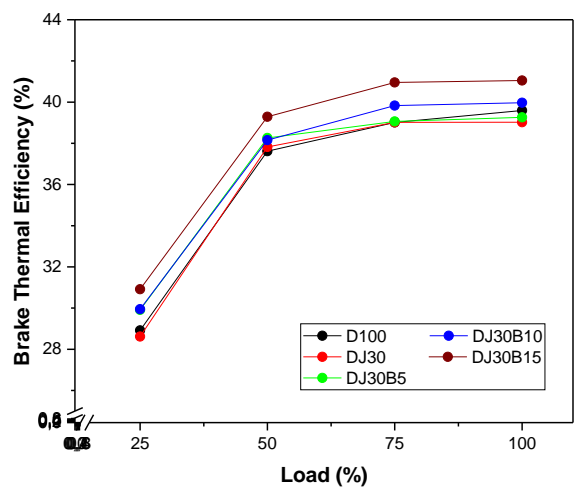

Gambar 11. Brake thermal efficiency mesin diesel berbahan bakar solar dengan kandungan jatropa 30\% dan butanol $5 \%, 10 \%, 15 \%$

Pengaruh butanol pada bahan bakar solar campuran jatropa 10\%, 20\% dan 30\% terhadap brake thermal effisiensi (BTE) terlihat pada Gambar 9. Gambar 10, dan Gambar 11. Secara umum, BTE mesin diesel mengalami peningkatan seiring kenaikan pembeban mesin. Hal ini terjadi pada tendensi brake power yang meningkat dan brake spesific fuel concumption yang menurun [21. Adanya kandungan oksigen menambah durasi ignition delay dan durasi proses pembakaran sehingga menghasilkan daya yang lebih baik dan brake efficiency thermal yang lebih baik $[22,11,8]$.

Gambar 9 merupakan pemaparan hasil pengujian brake thermal efficiency (BTE) mesin diesel berbahan bakar solar campuran jatropa $10 \%$ dan butanol $5 \%$, $10 \%$, dan $15 \%$. Peningkatan nilai BTE tertinggi terjadi pada penggunaan bahan bakar solar campuran jatropa $10 \%$ dengan kandungan butanol 15\% (DJ10B15) sebesar $8,7 \%$ saat pembebanan mesin $75 \%$. Sedangkan peningkatan nilai brake thermal efficiency (BTE) mesin diesel berbahan bakar solar campuran jatropa 20\% dan butanol 5\%, 10\%, dan 15\% (Gambar 10) terjadi pada bahan bakar dengan kandungan butanol 10\% (DJ20B10) sebesar 10,85\% saat pembebanan $25 \%$. Peningkatan yang sama juga terjadi pada penggunaan bahan bakar dengan campuran jatropa 30\% yaitu terjadi pada bahan bakaar dengan 
kandungan butanol 15\% (DJ30B15) sebesar $6,92 \%$ saat pembebanan $25 \%$.

\section{Kesimpulan}

Brake power mesin diesel berbahan bakar solar campuran jatropa dan butanol lebih tinggi dibandingkan D100 kecuali dengan kandungan jatropa $30 \%$. Peningkatan brake power tertinggi terjadi pada bahan bakar DJ10B15 sebesar 2,22\% saat pembebanan $75 \%$. Brake spesific fuel consumption mesin diesel berbahan bakar solar campuran jatropa dan butanol lebih rendah dibandingkan D100 kecuali dengan kandungan jatropa 30\%. Penurunan Brake spesific fuel consumption tertinggi terjadi pada bahan bakar DJ10B10 sebesar 4,81\% saat pembebanan $100 \%$. Brake thermal efficiency mesin diesel berbahan bakar solar campuran jatropa dan butanol lebih tinggi dibandingkan D100. Peningkatan Brake thermal efficiency tertinggi terjadi pada bahan bakar DJ20B10 sebesar 10,85\% saat pembebanan $25 \%$.

\section{Referensi}

[1] Syarifudin dan Syaiful, 2019. Daya dan emisi jelaga dari mesin diesel berbahan bakar solar-jatropabuthanol. Jurnal Rekayasa Mesin, vol. 14 , no. 3 .

[2] Madiwale, S. et al., 2018. Properties investigation and performance analysis of a diesel engine fuelled with jatropha, soybean, palm and cottonseed biodiesel using ethanol as an additive. Material Today: Proceedings 5, pp. 657-664.

[3] Lin, J., and Chen, Y., 2017. Production of biodiesel by transesterification of Jatropha oil with microwave heating. Journal of the Taiwan Institute of Chemical Engineers 75, pp. 43-50.

[4] Rashed, M.M. et al., 2016. Performance and emission characteristics of a diesel engine fueled with palm, jatropha, and moringa oil methyl ester. Industrial
Crops and Products 79, pp. 70-76.

[5] Gomaa, M. et al., 2011. Trade-off between nox, soot and egr rates for an IDI diesel engine fuelled with JB5. Journal of Applied Sciences 11, pp. 1987-1993.

[6] Darmana, E. dkk., 2013. Pengaruh cold EGR terhadap brake power pada mesin diesel dengan bahan bakar campuran solar dan jatropa. Eksergi Jurnal Teknik Energi, vol. 9, no.3.

[7] Hoang A.T. et al., 2019. A core correlation of spray characteristics, deposit formation, and combustion of a high-speed diesel engine fueled with Jatropha oil and diesel fuel. Fuel 244, pp. 159-175, 2019.

[8] Isik M.Z. et al., 2017. The effect of $n$ -butanol additive on low load combustion, performance and emissions of biodiesel-diesel blend in a heavy duty diesel power generator 90, pp. 174-184.

[9] Syarifudin et al., 2018. Effect of butanol on fuel consumption and smoke emission of direct injection diesel engine fueled by jatropha oil and diesel fuel blends with cold EGR system. SHS Web of Conferences 49, pp. 1-6.

[10] Imtenan, S. et al., 2015. Effect of nbutanol and diethyl ether as oxygenated additives on combustionemission-performance characteristics of a multiple cylinder diesel engine fuelled with diesel-jatropha biodiesel blend. Energy Conversion and Management 94, pp. 84-94.

[11] Ibrahim, A., 2016. Performance and combustion characteristics of a diesel engine fuelled by butanol-biodieseldiesel blends. Applied Thermal Engineering 103, pp. 651-659.

[12] El-seesy, A.I., and Hassan, H. 2019. Investigation of the effect of adding graphene oxide, graphene nanoplatelet, and multiwalled carbon nanotube additives with n-butanolJatropha methyl ester on a diesel engine performance. Renewable 
Energy 132, pp. 558-574.

[13] Heywood, J.B. 1988. Internal combustion engine fundamental, McGraw-Hill, Inc, United States of America.

[14] Xue, J. et al., 2011. Effect of biodiesel on engine performances and emissions 15, pp. 1098-1116.

[15] Syarifudin \& Syaiful. Performance and soot emissions from direct injection diesel engine fueled by diesel-jatropha-butanol-blended

diesel fuel Performance and soot emissions from direct injection diesel engine fueled by diesel-jatrophabutanol-blended diesel fuel. Journal Physich: Conference Series, 2020.

[16] Algayyim, S.J.M. et al., 2018. Impact of butanol-acetone mixture as a fuel additive on diesel engine performance and emissions. Fuel 227, pp. 118-126.

[17] Fayad, M. A. et al., 2017. Manipulating modern diesel engine particulate emission characteristics through butanol fuel blending and fuel injection strategies for efficient diesel oxidation catalysts. Applied Energy 190, pp. 490-500.

[18] Ileri, E. 2016. Comparative analyses of n-butanol e rapeseed oil e diesel blend with biodiesel, diesel and biodiesel e diesel fuels in a turbocharged direct injection diesel engine. Journal of the Energy Institute 89, pp. 586-593.

[19] Satsangi, D.P., and Tiwari, N. 2018. Experimental investigation on combustion, noise, vibrations, performance and emissions characteristics of diesel / n-butanol blends driven genset engine. Fuel 221, pp. 44-60.

[20] Tan, Y.H., et al., 2017. Engine performance and emissions characteristics of a diesel engine fueled with diesel-biodieselbioethanol emulsions. Energy Conversion and Management 132, pp. 54-64.
[21] Li, S. et al. 2019. Effects of gasoline and iso-butanol addition on combustion and pollutant emissions of a common-rail diesel engine at different injection timing. Fuel 256, pp. 1-11.

[22] Huang, H. 2019. E ff ects of EGR rates on combustion and emission characteristics in a diesel engine with n-butanol / PODE 3-4 / diesel blends. Applied Thermal Engineering 146, pp. 212-222. 